\title{
Scouting Interactive Games for Scouts Based on Embodied Interaction Using Embedded System
}

\author{
*Iwan Kurnianto Wibowo, Muhammad Andan Cahyo \\ Politeknik Elektronika Negeri Surabaya (PENS), Indonesia \\ Email:*eone@pens.ac.id, andancahyo@gmail.com
}

Received January 29, 2021; Revised March 3, 2021; Accepted April 10, 2021

\begin{abstract}
Scouts is the scouting level after the cub scout aged 11-15 years old. In their age range, they can use logical thinking in the form of physical objects to solve a problem. The development of the Scout Movement has had ups and downs, and recently the number of children interest in scouting activities decreases. The impact is the scouting insight they get isn't optimal. One strategy to solve this problem is by developed forms, tools, and learning media of scouting. Game is one of the learning media that can be used to create effective learning. The educational game is a popular learning media and widely developed by experts, as well as in Indonesia. Unfortunately, in the field of scouting, educational games are less developed. In this research, the author will build an educational scouting game for scouts. In the scouts level, they began to be introduced about communication code, skills, natural recognition, and others. Games created using Embodied Interaction technology. This technology allows users to control the game using body movement. The purpose of this game is to increase the interest and insight of children on Scout activities. From the results of research that has been done, it can be seen that after playing the game, $95,7 \%$ of children thought it is exciting, and $87 \%$ of them became enthusiastic join scouting activity. Based on the results of the pre-test and post-test, scouting insight increased after playing the game with an average percentage of increased insight being $18.7 \%$.
\end{abstract}

Keywords: scouts, game, educative, embodied interaction.

\section{INTRODUCTION}

The development of science and technology encourages the learning process to be more attractive and applicable. The innovation of appropriate learning methods can help the learning process of learners for the sake of science is absorbed easily in terms of everyday life. One way to encourage the achievement of effective learning is to use the help of learning media. Game is one of the media that we can use to create effective learning. Characteristics of games that fun make many people like it, as well as children. 
One of the current gaming trends is the Microsoft Kinect and the Nintendo Wii to control game character [1]. Both lead to a game interface that leverages the player's knowledge and skills to create a natural and intuitive experience[2]. Educational games are popular learning media that are commonly being developed by experts. Unfortunately, in the field of scouting, educational games are less developed. Some games about scouting have already been created, but the game's material only focuses on one topic, the type is a puzzle game, and the way of delivery is less attractive [3]. Games can attract children's attention by using smart object media as a medium for interaction with various scenarios [4]. For example, mobile games, Virtual Reality, AI, and Embodied Interaction. Since many years, learning and development have been supported by physical activity and manipulation of physical objects. With the growing popularity of embedded technology, opportunities to use embodied interaction or tangible interactions for learning and development have emerged. [5]

Scouts have an important role in fostering student discipline. Students are taught to be disciplined and obey the existing rules through an interesting scouting activity [6]. Scouts is a level of scout after the Cub Scout. The member of scouts are 11-15 years old or from grade 4-6 Elementary school and grade 7-9 Junior High school. At this level, they begin to be introduced to scouting activities such as communication codes, skills, natural recognition, and so on. Based on Erick H Erikson's theory about individual psychosocial development and Jean Piaget on children's cognitive development, educational games would be effective if applied to scouts of grade 4-6 elementary school (children aged 10-12 years). Because children at that age are progressing psychosocial aspects of industry vs. inferiority and they have also been able to use logical thinking to run a problem. This age is the perfect time to control children's emotions. Given the participation of children in the class affected by the emotional health of the child itself[7].

From the problems that have been presented in this background, then in this research author made a scout shaped learning media game with the application of Embodied Interaction technology as a game controller. The game design aspect [8], [9] is approached by adopting an embodied interaction lens [10] and an embedded system to identify the underlying humanistic factors that these patterns depend on. By playing this game, children can get the experience of playing an educational, fun, and attractive game in order to create effective learning that can increase the enthusiasm of users to follow the scout activities.

\section{RELATED WORKS}

Fuada [3] proposed scout games with an initial study of digital game design. The scope is limited to the concept and design stages. The game genre is an adventure and educational game that can be used as a complement to previously made applications, where players are directed to complete the steps of moral values from one of the Dasa Darma Pramuka. The output of 
this game provides benefits, especially teachers and students, or the wider community who are reached by technology. Furthermore, it can make scout learning done in class or outside the classroom without the help of the teacher. This study uses a development model consisting of the concept, design, material collecting, assembly, testing, and distribution. Huda [11] conducted research to determine the relationship between physics concepts in scout games. The results of the analysis show that there are physical concepts in the form of assessment, bonfire, mapping, and ball throwing. This is considered to be able to improve thinking skills in students.

Currently, many studies are exploring the design and evaluation of embodied interaction to support learning and development [12], [13]. Resnick et al. have introduced an early example of a tangible interface developed for education [14]. They invented digital manipulatives computationally enhanced toys that let children explore scientific concepts in fun ways. Another example of embodied interaction for educational media focuses on learning mathematical principles. Embodied interaction is also an interaction style that is often explored for manipulating sound and music in a game. This media can attract attention from the user so that the learning material can be captured quickly and pleasantly.

Bakker et al. study explored an interactive design approach to learning system design with an embodied metaphor-based interaction model. The interaction model determines the mapping between input actions and output responses in a system [5]. Horn and Jacob [15] proposed a tangible system consisting of jigsaw puzzles such as artifacts. This artifact is used to create a simple computer program. Girouard et al. [16] described a tangible interface designed to explore the surface of 3D objects. This interface is named SmartBlocks.

Wibowo [4] presented a communication platform on the smart object that has been built. The communication platform includes the smart object mechanism in serving interactions with other smart objects and communication with the server. Smart objects function as universal input and output devices based on embedded systems that are embedded in a communication protocol. Smart objects are physically integrated with sensors, processors, and networks. Smart objects are able to sense, interpret what is happening to themselves and their environment, react, interact with other objects, and exchange information with users [17]. Media interaction is closely related to the communication platform used.

Yin and $\mathrm{Xu}$ [18] proposed a game that can recognize upper limb movements, observe recovery stages, and recommend a patient's appropriate training prescriptions based on their condition. Apart from that, it can also record the patient's historical information and take various game challenges to different stages of recovery. The movement of the upper limbs was read using the IMU sensor. Research of [19] uses a low cost IMU sensor node in a game to increase patient motivation in healing knee surgery. The IMU sensor 
is placed on the patient's knee and monitored by a physiotherapist remotely. IMU sensor generates roll, pitch, and yaw orientation data in real-time.

\section{ORIGINALITY}

In Indonesia, almost scout games only focus on learning materials without paying attention to the interactions that occur between users and computers. Even though scouts always prioritize physical activity. As a contribution, we designed an educational game that presents physical or embodied interactions to attract the attention of students in scout learning from an early age. Physical interaction will take users to a new level of gaming experience, where embedded system technology will bring users closer to interacting with hardware. Embedded systems provide real-time, control, and monitoring support for larger systems. This game uses IMU sensor to recognize the gesture. Game experiences involve a variety of activities. The main activity is how the user interacts with the game itself.

In addition, this game is relatively easy to run using scouting materials for each challenge. It is equipped with exciting scenarios based on the basics of scouting and HCI analysis. In the scouts level, students began to be introduced about communication code, skills, natural recognition, and others.

\section{SYSTEM DESIGN}

This game has the story of a scout who lost in the forest and had to return to the camp by way of the forest. The challenge in this game is how the scout can come back by solving the mission that exists using his scout insight. In making a game for kids, there are various stages to be done to produce an effective learning medium for them. The stages include:

\subsection{Education Games Material for Scouts}

The scouting material presented inside the game is a scout (Penggalang) material that has been adapted from the syllabus. The materials that served are:

Table 1. Scouts Syllabus

\begin{tabular}{|l|l|l|l|}
\hline No & Academic Subject & Competence Standart & Basic Competence \\
\hline 1 & $\begin{array}{l}\text { History of Scouts } \\
\text { and Code of Honor }\end{array}$ & $\begin{array}{l}\text { Understand the history of } \\
\text { the founding of the Scouts } \\
\text { Practice the scout honor } \\
\text { code in daily life. }\end{array}$ & $\begin{array}{l}\text { Understand the short } \\
\text { history of the International } \\
\text { scouts } \\
\text { Understand the short } \\
\text { history of the Indonesian } \\
\text { scouts }\end{array}$ \\
\hline 2 & Scouting Skills & $\begin{array}{l}\text { - Morse and Semaphore } \\
\text { Trail Marks and Map use } \\
\text { comonstrate } \\
\text { codemaphore } \\
\text { Know the trail and the map } \\
\text { in the scouting } \\
\text { Use the trail and the map in } \\
\text { the scouting }\end{array}$ \\
\hline 3 & Technology & $\bullet$ Water Rocket & $\begin{array}{l}\text { Know how to make and } \\
\text { launch a water rocket }\end{array}$ \\
\hline
\end{tabular}




\subsection{Embedded System Architecture}

Embedded systems are used to support the physical interaction process between users and computers. In this case, embedded systems are implemented using a microcontroller. Embedded systems can provide realtime responses. So that sensor data acquisition, wireless data transmission, and control of several tasks can be done in real-time.

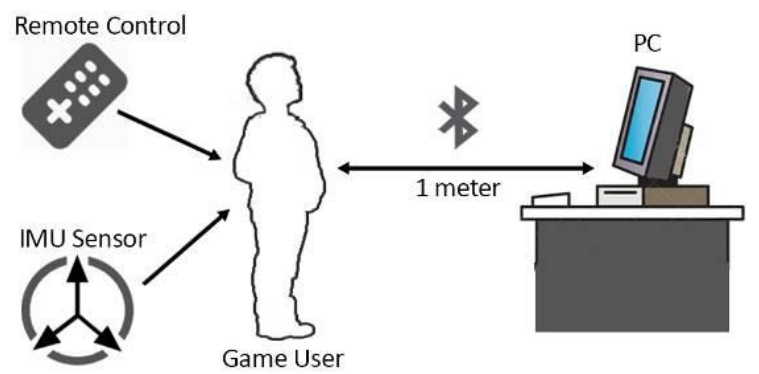

Figure 1. System illustration

System illustration can be seen in Figure 1. To get physical interaction in the game, the user must stand while playing. The distance between the user and the computer is about 1 meter. So that you will get flexibility in moving. Body movements will be read by the Inertial Measurement Unit (IMU) sensors and sent to the computer. In addition to IMU, there is also a remote control that is used as an aid when selecting the game menu. Data transmission using Bluetooth connection. The data from the user will be sent to the game machine using this connection line. Then converted to HID, so that the resulting output is keyboard data.

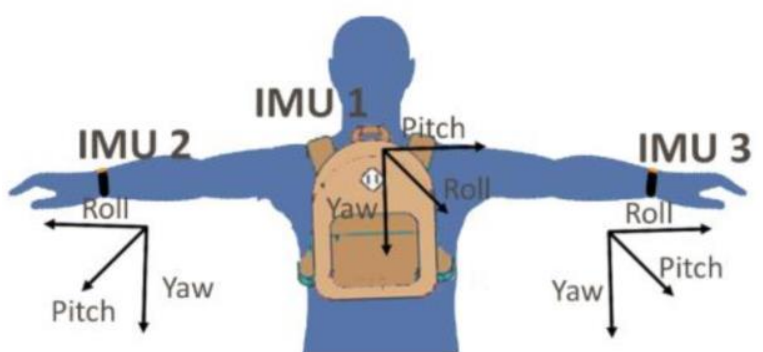

Figure 2. Embodied interaction with IMU Sensor attached to user body

Game control uses embodied interaction, where users will play games using body movement as shown in Figure 2. The elements used to support this feature are 3 IMU sensors attached to the user's body. The first IMU is placed in a bag that is used by the user. The purpose of this 1st IMU is to control the movement of characters when the game is played. At the same time, the remaining two IMU each placed on the wrist of the right and left of the user. The purpose of those IMU is to detect the sign of semaphore. It is one of the challenges presented by the game.

IMU is an electronic device that functions to measures and reports the craft's speed, orientation, and force of gravitational, using a combination of 
an accelerometer, gyroscope and magnetometer. The IMU is usually used as a major component of aircraft, water vehicles, and missiles. And IMU is also used for inertial sensors for robots [20].

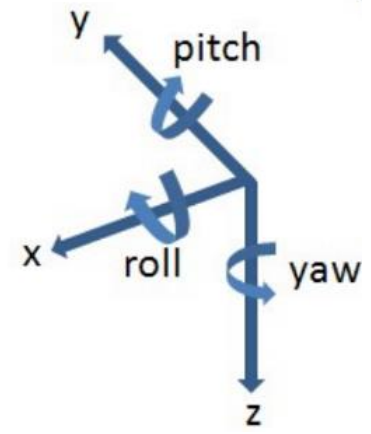

Figure 3. Roll, Pitch and Yaw motion schemes

IMU can provide Roll, Pitch and Yaw motion schemes as shown in Figure 3. Yaw is the inertial framework rotation of the z-axis by angle $\psi$. The yaw rotation provides a new frame coordinates where the z-axis is parallel to the inertial frame while the x-axis and y-axis are rotated by the yaw angle $\psi$. The pitch represents the rotation of the $y$-axis with the angle $\theta$. Roll is the inertial frame rotation of the $\mathrm{x}$-axis by angle $\varphi$.

\subsection{Game Controls with Embodied Interaction}

Embodied Interaction is described as an attempt to "move the computation and interaction of the abstract cognitive process world into a phenomenal world similar to our kind of interaction"[10]. Embodied Interaction can be interpreted as the creation of manipulation through interaction by involving the limbs to provide input to the computer. In this case, the user does not feel interacting with the computer, but rather acts in a non-digital physical world. Embodied Interaction equipment can be manifested in various ways such as speech, eye movement, and certain gestures.

In general, the interaction process can be divided into 5 dimensions, including:

1. Explicitness. This interaction model is the most common way to interact with computers.

2. Input Mode. various models input can be used for equipment, such as the hand used as input to move an object, other parts of the body are used to carry out an action under certain conditions, etc.

3. Granularity. Depending on the form of interaction, multiple commands can be encoded.

4. Privacy. Embodied interaction tools can easily observe what we do, depending on what input model is used

5. Proximity. Interaction can occur in a certain distance variation. 
To play the game, the user must use game console. The stages that must be done to play the game using the console is as follows:

1. Users stand facing directly in front of the computer with a distance of approximately 1 meter.

2. Make sure the master console board in the bag is on, and the slave console board is connected to the computer.

3. Wear the IMU in each left and right hand, then connect the bracelet with the cable coming from the master console board.

4. Extend the hand until both hands are straight, then press the red button on the remote to perform IMU calibration.

5. At this stage, the console can already be used to play the game. To move the game player to the right then tilt the body to the right and to move the player to the left, then tilt the body to the left.

6. To convert the console to semaphore mode, press the red and yellow buttons simultaneously on the remote and to return it to normal mode then press red and yellow button together again.

To convert the console to rocket mode, press the green and yellow buttons simultaneously on the remote and to return it to normal mode then press the green and yellow buttons simultaneously.

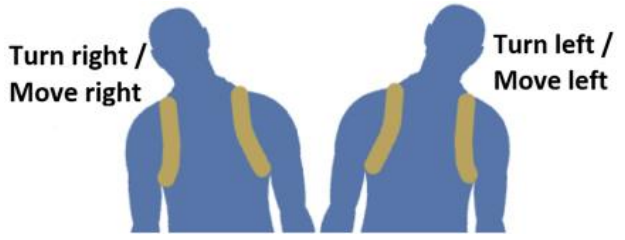

Figure 4. User body motion to move game characters

During the game, to move the character to the right or left use body movements, as shown in Figure 4.

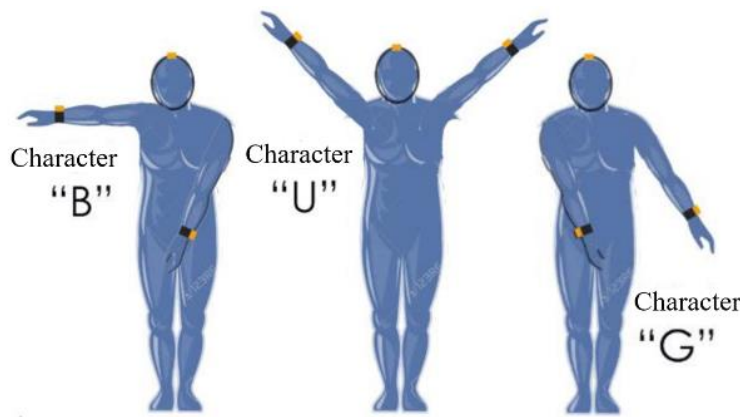

Figure 5. Semaphore formation

One of the challenges that must be faced is the semaphore code. It requires two-handed gestures of the user to form certain alphabets precisely as shown in Figure 5. The IMU2 and IMU3 sensors read the movement and orientation of the user's two hands and are sent to a computer to be translated as a semaphore formation. 


\subsection{Game Scenario}

This game consists of 3 levels, and each level will be presented scout level creature material that has been adapted from the syllabus. From these materials, then the author made the game story "Petualang Pramuka Penggalang." It tells that the scouts students of Puspa Melati Elementary School attend a camp. One day they held nature exploration in the forest with the aim is they are more familiar with nature. In the middle of exploring, one member named Jojo apart from the group, as a result, he lost in the forest. The main mission of this game is how to get Jojo back into the camp by relying on the insight of the gamer has. Because he is lost in the forest, there are many dangerous threats, so he must hurry back before sunset by running as fast as possible.

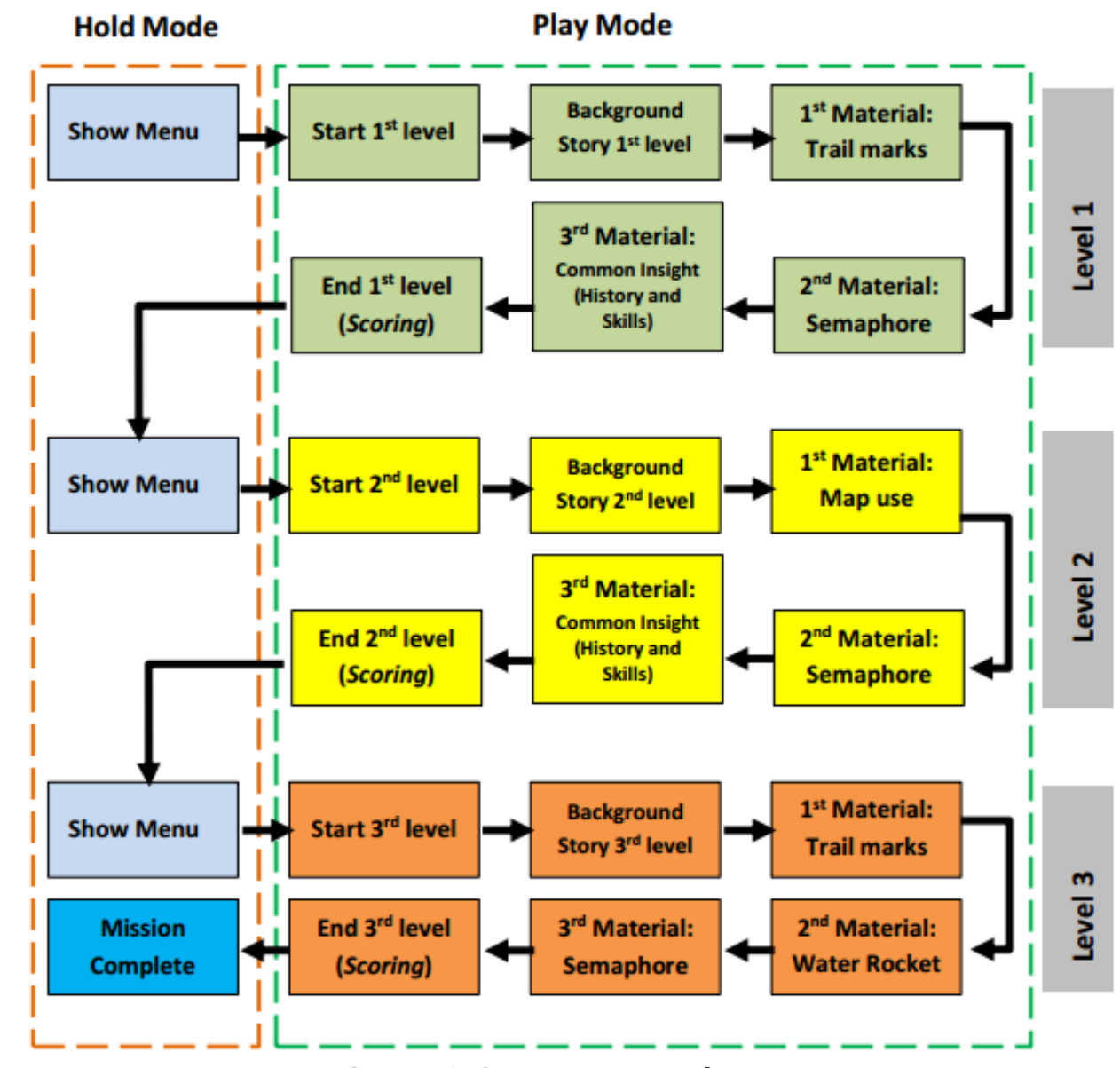

Figure 6. Game scenario diagram

\subsection{Game Interface}

The interface is an important part in the game. With the interface, the game and the user can interact with each other. Figure 7 show interface scenes of main menu, level 1-3, water rocket and semaphore learning. In the menu there are various features that can be selected such as Play, Buy Item and Game Instructions. In level 1, player has to solve the scout challenge such as trail marks, semaphore and common knowledge of scouts. The player has 
to solve the scout challenge such as read the map, semaphore, and common knowledge of scouts in the level 2. In level 3, the player has to solve the scout challenge such as trail marks, semaphore, and water rocket. Game display at the end of level 3, the player must be able to fire the water rocket until it touches the bell in the monitoring building. The last scene is an example of applying semaphore learning to games. Players will demonstrate semaphore cues to open the gates in order to proceed to the next stage.

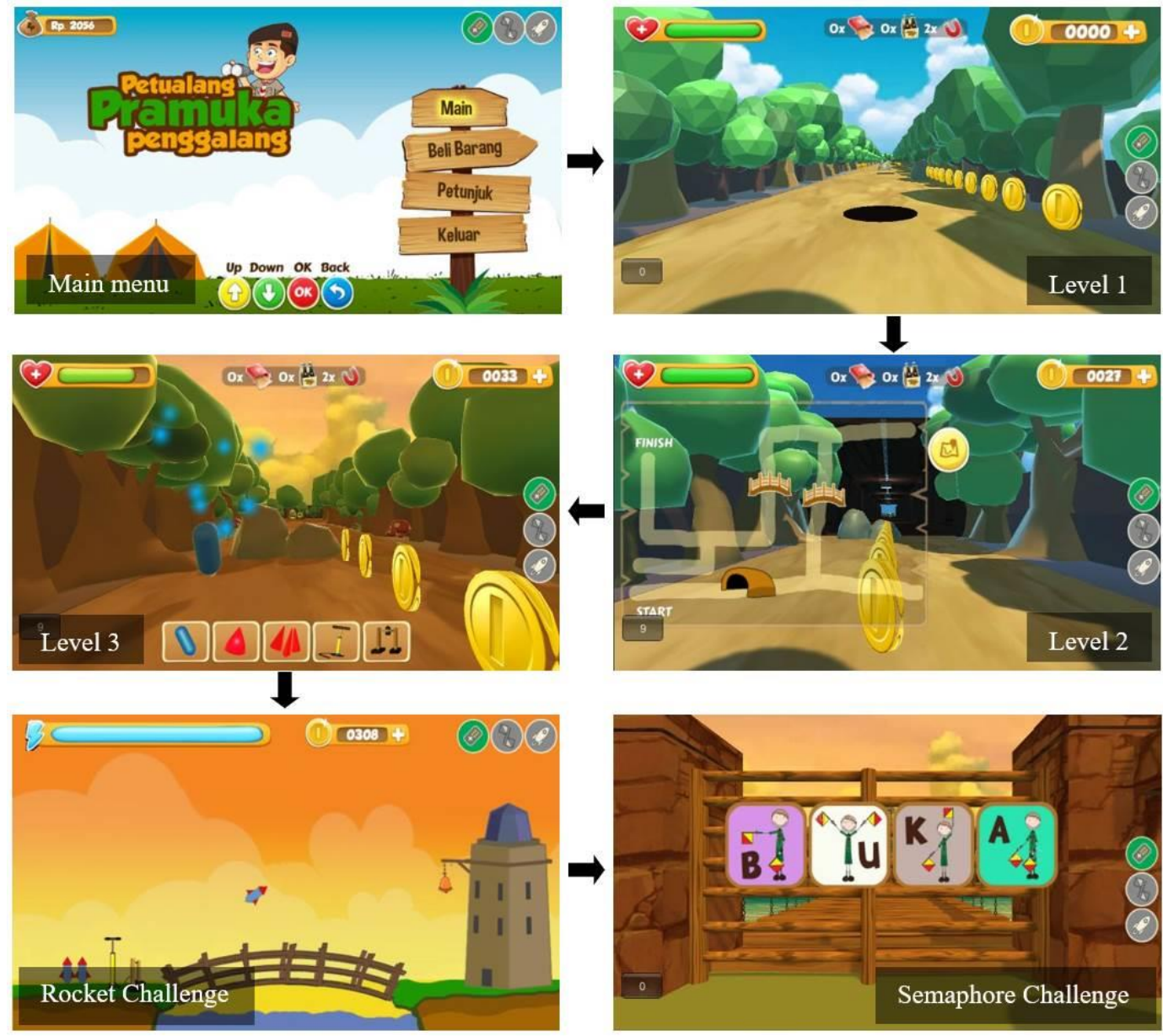

Figure 7. Scenes of the game

\section{EXPERIMENT AND ANALYSIS}

To find out whether the game system has been running as expected, then the researchers conducted several tests related to game performance and game impact for children. Here are the test results that have been done.

\subsection{Embedded Sistem Testing}

\section{a. Controller Performance Testing}

Console game testing is done by taking data from the remote button and IMU on the Master Console and then sent to the Slave Console via bluetooth connection. The data on the Slave Console is converted to HID keyboard input and sent to the PC. 
Data from remote that is converted to HID keyboard input are :

- Red button of the remote produces keyboard input 'M'

- Blue button of the remote produces keyboard input 'B'

- Yellow button of the remote produces keyboard input ' $K$ '

- Green button of the remote produces keyboard input 'H'

- Roll data on IMU of <-25 produces keyboard input "Left Arrow"

- Roll data on IMU of $>25^{\circ}$ produces keyboard input "Right Arrow"

Based on the console game testing results in Table 2, we can conclude that the console runs well. Almost all commands are executed properly. Check mark $(\sqrt{ })$ means that the system has successfully detected the input button until it is converted to HID data. Meanwhile, a cross mark ( $\mathrm{x}$ ) indicates that the system has failed to detect the input. The latency level is at $10 \mathrm{~ms}$ and data is sent if there is a sensor data change event.

Table 2. Controller testing result

\begin{tabular}{|c|l|l|l|l|l|l|}
\hline No & Input M & Input B & Input K & Input H & Left Arrow & Right Arrow \\
\hline 1 & $\sqrt{ }$ & $\sqrt{ }$ & $\sqrt{ }$ & $\sqrt{ }$ & $\sqrt{ }$ & $\sqrt{ }$ \\
\hline 2 & $\sqrt{ }$ & $\sqrt{ }$ & $\sqrt{ }$ & $\sqrt{ }$ & $\sqrt{ }$ & $\sqrt{ }$ \\
\hline 3 & $\sqrt{ }$ & $\sqrt{ }$ & $\sqrt{ }$ & $\sqrt{ }$ & $\sqrt{ }$ & $\sqrt{ }$ \\
\hline 4 & $\sqrt{ }$ & $\sqrt{ }$ & $\sqrt{ }$ & $\sqrt{ }$ & $\sqrt{ }$ & $\sqrt{ }$ \\
\hline 5 & $\sqrt{ }$ & $\sqrt{ }$ & $\sqrt{ }$ & $\sqrt{ }$ & $\sqrt{ }$ & $\sqrt{ }$ \\
\hline 6 & $\sqrt{ }$ & $\sqrt{ }$ & $\sqrt{ }$ & $\sqrt{ }$ & $\sqrt{ }$ & $\sqrt{ }$ \\
\hline 7 & $\sqrt{ }$ & $\sqrt{ }$ & $\sqrt{ }$ & $\sqrt{ }$ & $\sqrt{ }$ & $\sqrt{ }$ \\
\hline 8 & $\sqrt{ }$ & $\mathrm{x}$ & $\sqrt{ }$ & $\sqrt{ }$ & $\sqrt{ }$ & $\sqrt{ }$ \\
\hline 9 & $\sqrt{ }$ & $\sqrt{ }$ & $\sqrt{ }$ & $\sqrt{ }$ & $\sqrt{ }$ & $\sqrt{ }$ \\
\hline 10 & $\sqrt{ }$ & $\sqrt{ }$ & $\sqrt{ }$ & $\sqrt{ }$ & $\sqrt{ }$ & $\sqrt{ }$ \\
\hline 11 & $\mathrm{x}$ & $\sqrt{ }$ & $\sqrt{ }$ & $\sqrt{ }$ & $\sqrt{ }$ & $\sqrt{ }$ \\
\hline 12 & $\sqrt{ }$ & $\sqrt{ }$ & $\sqrt{ }$ & $\sqrt{ }$ & $\sqrt{ }$ & $\sqrt{ }$ \\
\hline 13 & $\sqrt{ }$ & $\sqrt{ }$ & $\sqrt{ }$ & $\sqrt{ }$ & $\sqrt{ }$ & $\sqrt{ }$ \\
\hline 14 & $\sqrt{ }$ & $\sqrt{ }$ & $\sqrt{ }$ & $\sqrt{ }$ & $\sqrt{ }$ & $\sqrt{ }$ \\
\hline 15 & $\sqrt{ }$ & $\sqrt{ }$ & $\sqrt{ }$ & $\sqrt{ }$ & $\sqrt{ }$ & $\sqrt{ }$ \\
\hline
\end{tabular}

Please note that the IMU sensor (yaw, roll and pitch) used has resolution $0.01^{\circ}$, measurement error $\pm 1^{\circ}$ and frequency response $100 \mathrm{~Hz}$ (115200bps).

\section{b. Data Transmission Testing}

Data transmission from remote to $\mathrm{PC}$ is done using bluetooth module wirelessly. The Bluetooth device used on the console has a signal that is strong enough to reach other Bluetooth devices (bluetooth slave) at a very close or quite far distance $(10.5 \mathrm{~m})$. This test is done to find out how accurate the data received by the slave console is every one unit of time which is done repeatedly. The test was carried out twice with the amount of time lag between different data transmissions. In the first test, data is sent to the slave 
console every $50 \mathrm{~ms}$ and in the second test, the sending time is increased by $100 \mathrm{~ms}$.

Table 3. Data transmission of console every $50 \mathrm{~ms}$ and $100 \mathrm{~ms}$

\begin{tabular}{|c|c|c|c|}
\hline \multirow{2}{*}{$\begin{array}{c}\text { Data } \\
\text { No. }\end{array}$} & \multirow{2}{*}{ Data sent } & \multicolumn{2}{|c|}{ Data received (after parsing) } \\
\hline & & Interval $50 \mathrm{~ms}$ & Interval $100 \mathrm{~ms}$ \\
\hline 1 & \#!Test & Test & Test \\
\hline 2 & \#!Test & Tdst & Test \\
\hline 3 & \#!Test & Te.- ÿ\#!Test & Test \\
\hline 4 & \#!Test & Tdst & Test \\
\hline 5 & \#!Test & Test & Test \\
\hline 6 & \#!Test〜 & Test & Test \\
\hline 7 & \#!Test〜 & Test & Test \\
\hline 8 & \#!Test & Test & Test \\
\hline 9 & $\# !$ Test & Test & Test \\
\hline 10 & \#!Test & Test & Test \\
\hline 11 & \#!Test & Tdst & Test \\
\hline 12 & \#!Test & Test & Test \\
\hline 13 & $\# !$ Test & Test & Test \\
\hline 14 & \#!Test & Test & Test \\
\hline 15 & \#!Test & Test & Test \\
\hline
\end{tabular}

Based on the test results shown in Table 3, it can be observed that data transmission with too short a time lag results in a lot of data damage. This is because the receiving console takes time to parse the received data. Before the parsing process is complete, other data that have just entered will interrupt it. Conversely, if the lag time is longer, the data received is more accurate.

\subsection{User testing}

This test is done by determining the reaction of children that play the game. Game testing is done to 23 students of primary school belonging to scout gamers from grades 4 to 6 . The mechanisms performed to obtain the test data are:

1. Students do a Pre-test to know their early insight before playing the game.

2. Students play the game and have to complete all levels.

3. Students do Post-test that is used to know the insight of children after playing the game.

4. After that, each child will be interviewed by the observer regarding game performance.

The observer interviews the object of research to know the performance of games that they feel after playing the game. Some parameters of the questions asked and the results are: 
Table 4. Game performance testing result

\begin{tabular}{|c|l|l|}
\hline No. & \multicolumn{1}{|c|}{ Parameter } & $\begin{array}{c}\text { \% Response } \\
\text { (Agree / Good) }\end{array}$ \\
\hline 1 & Aware the benefits of scouting & $91,3 \%$ \\
\hline 2 & Enthusiast join scouting in school & $87,0 \%$ \\
\hline 3 & Enthusiastic learn scouting from game & $95,7 \%$ \\
\hline 4 & New Experiences playing scouting game & $97,8 \%$ \\
\hline 5 & Challenged play the game & $60,9 \%$ \\
\hline 6 & Easy to play the game & $62,3 \%$ \\
\hline 7 & Think the game has good graphics & $100 \%$ \\
\hline 8 & Think the game is interesting & $95,7 \%$ \\
\hline 9 & Game instructions are understandable & $84,8 \%$ \\
\hline 10 & Game console comfortable & $85,5 \%$ \\
\hline
\end{tabular}

From Table 4 we can observe that $>90 \%$ of children who have tried to play the game are aware that many benefits are gained if they follow scouting, and $>85 \%$ of them become enthusiastic about following the Scout activities. The majority of them like to learn scouts through this game, proved by $>95 \%$ of them answered learning scout by game is fun. Almost all children who try to play game scouting with this body control thought it is something new. From the level of challenge and ease of play, they consider this game quite challenging and easy, even though some of them feel less challenged and have difficulty playing the game. According to our observation, this occurs because children are used to games on smartphones that only move their fingers. So it takes longer adaptation time. And from the results of this test, some improvements are needed in this game going forward. In terms of appearance, all children love game graphics and the majority of them find it is interesting. $>80 \%$ consider the instructions and language used understandable. And $>85 \%$ of children who wear the games console felt comfort use it.

\subsection{Impact of the Game on Scouting Insight of the children}

Aside from being an entertainment element, games that are created also contain learning elements. The learning material presented is the scouting material of the Scout. Before playing the game, the children do the Pre-test first. The goal is to find out their level of insight about the material to be taught. Pre-test consists of 4 parts of the material, namely, History Scouting, Code of Honor \& General Knowledge, Skill Scouting, Semaphore Code, and Water Rocket Technology.

After completing all levels in the game, the test sample is working on Post-test questions. The goal is to find out whether the scouting science taught by games can be absorbed properly. Here are the results of Pre-test and Post-test that has been done: 


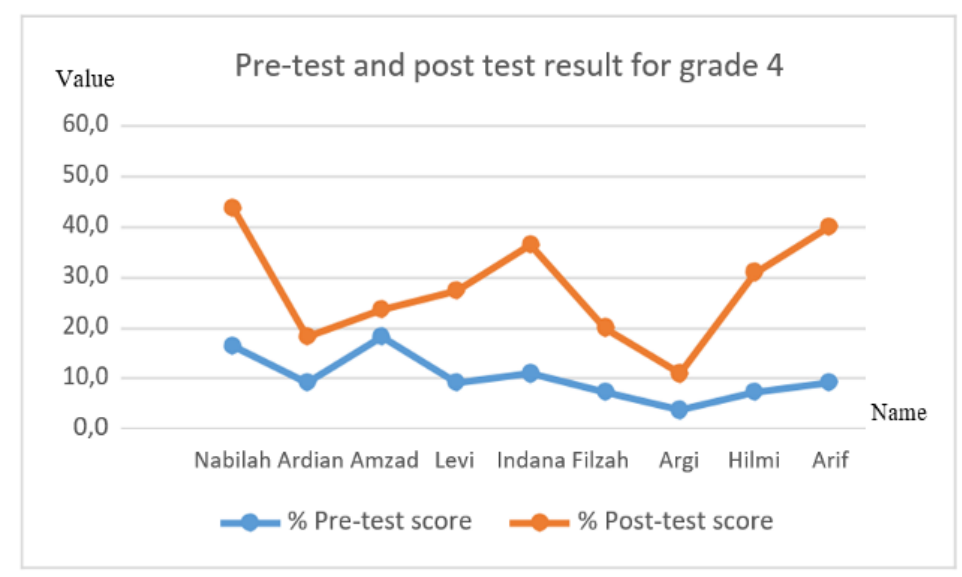

Figure 8. Graph of Pre-test and Post-test results for grade 4

Based on the pre-test results shown in Figure 8, it can be observed that many grade 4 children have less scouting insight into the material to be taught. All children could only answer pre-test questions for less than $20 \%$ of the total questions. Meanwhile, seen from the results of the post-test, all grade 4 children experienced an increase in scores with the highest post-test score attainment of $>40 \%$ of the questions answered from all the questions presented.

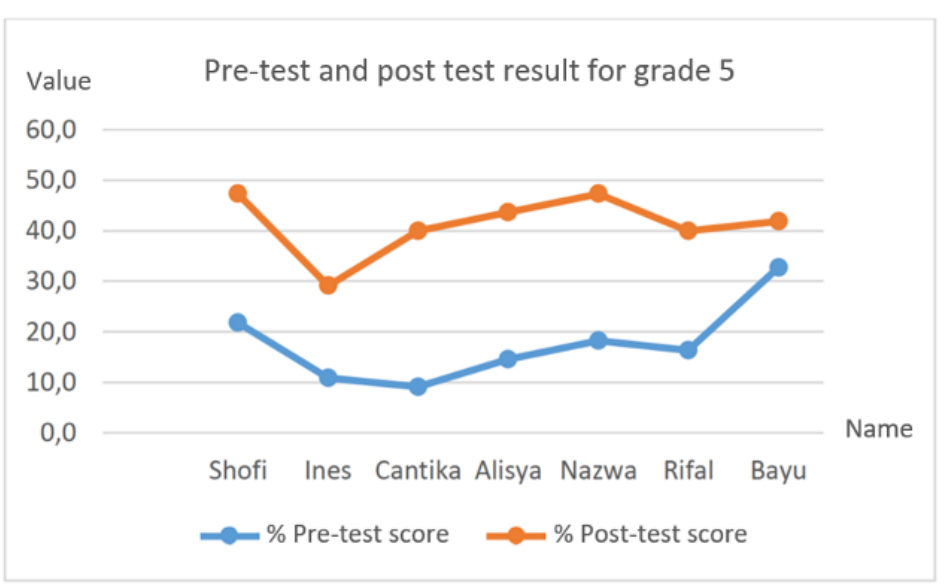

Figure 9. Graph of Pre-test and Post-test results for grade 5

For grade 5 students, it can be observed that many students lack scouting insight into the material to be taught. The majority of children could only answer pre-test questions for less than $20 \%$ of the total questions, namely 5 out of 7 children. Meanwhile, seen from the results of the post-test, all children experienced an increase in scores with the majority of the posttest scores obtained $>40 \%$ of the total questions that were done. 


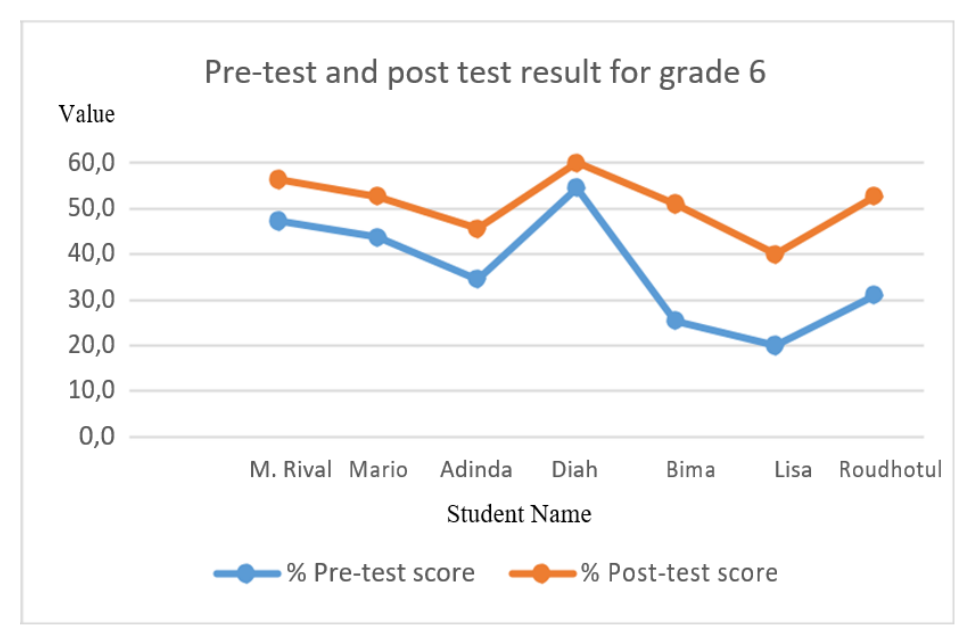

Figure 10. Graph of Pre-test and Post-test results for grade 6

Based on the pre-test results shown in Figure 10, the scouting insight of grade 6 students is considered insufficient even though the majority is still higher than grades 4 and 5 . This can be proven from their pre-test results whose average score is $>30 \%$ compared to Grade 4 and 5 who are below $20 \%$, namely 5 out of 7 children whose pre-test score is $>30 \%$. Meanwhile, seen from the results of the post-test, all children experienced an increase in value with the majority of the post-test scores obtained were $>40 \%$ of the total questions that were done with the highest score reaching $60 \%$ of the questions answered.

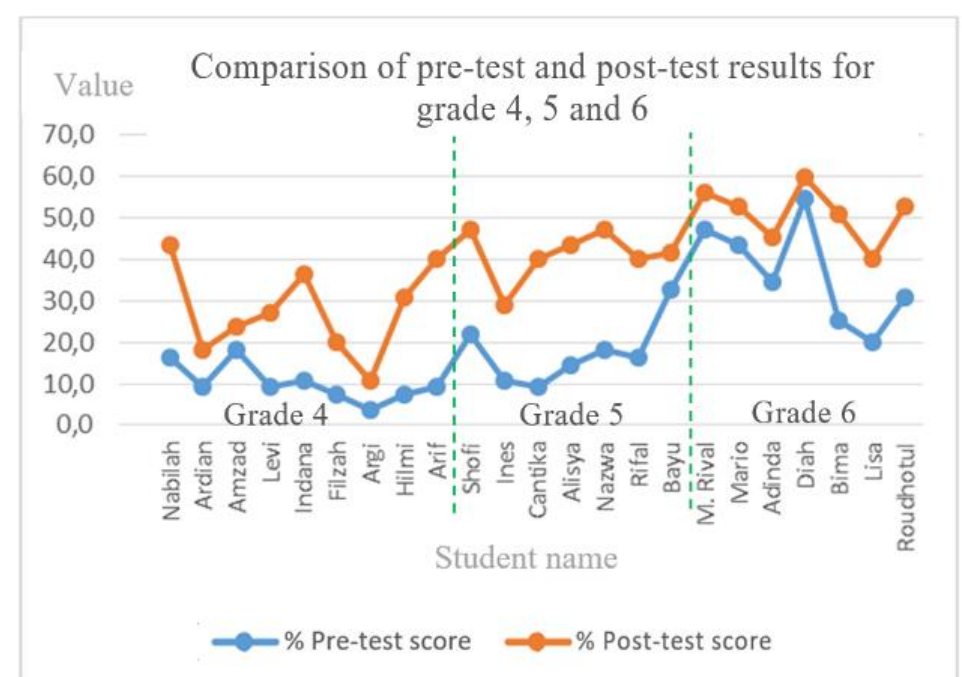

Figure 11. Comparison of pre-test and post-test results for grade 4, 5 and 6

After data of grade 4.5 and 6 are combined, the resulting Pre-test and post-test results are shown in Figure 11. The increase in insight in grade 5 is higher than in grades 4 and 6 . According to the graph, it can be concluded that all children who try the game "Petualang Pramuka Penggalang" increased their scouting insight. 


\subsection{Human Computer Interaction Design Analysis}

In designing this research, the application of HCI aspects are also considered such as Human Characteristics and Computer systems and interface architecture

\section{a. Human Information Processing}

In designing the HCI device, it is necessary to pay attention to the characteristics of users in processing information. Because game users are children, the information should be clear and adapted to their cognitive level. At the concrete operational cognitive development stage (for ages 6-12 years), children are mature enough to use logical thinking or operations, but only for physical objects that exist today. Without a physical object in front of them, children at this stage still have great difficulty completing logical tasks. In its application in the game, an example occurs when children are faced with problems choosing the right path while at a T-junction. Here they are assisted by the traces around the T-junction as shown in Figure 12.

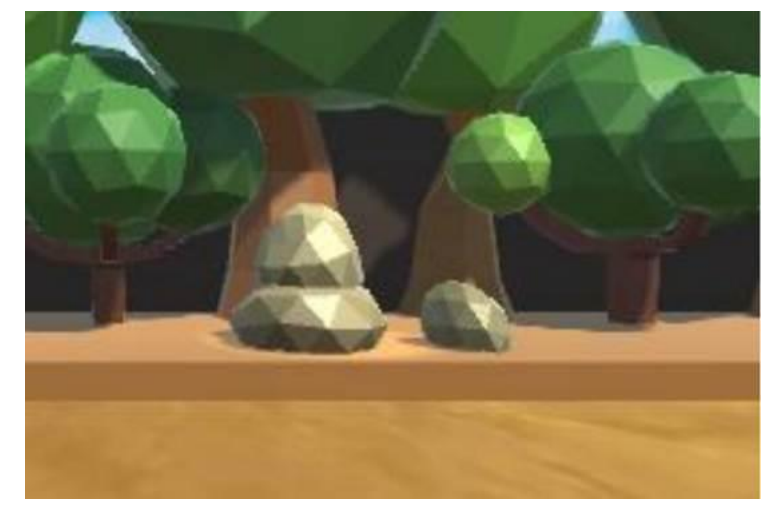

Figure 12. Track marks as physical objects for direction

The track marks are in the form of stones arranged in such a way that they have certain characteristics and purposes. The meaning of the trail mark is that the correct path is on the right. The stack of stones is a physical object that children can see and think logically. So that the child will easily determine the meaning of the trail marks and can distinguish different stone arrangements if they meet them in other places.

\section{b. Language, Communication, and Interaction}

In this game, the language used for instructions and features is mostly Indonesian because the user is Indonesian. Some of the features use English because they consider the mental model the user has. As an example of the game instructions shown in Figure 7, we can see that the menu options are in Indonesian so that children can easily and quickly understand them. Whereas on the remote navigation button there is a button description that uses English terms because the mental model of the user is more familiar with the English term than in Indonesian. 


\section{c. Ergonomics}

Ergonomics is a study that deals with the design of equipment and tasks that match human capabilities related to work comfort factors. There are several aspects of ergonomics that are applied, for example, control and display settings and the work environment. Game controls are grouped by function and frequency. Grouping of Features and Menus is carried out by function. The grouping in the Master Console interface design is shown in Figure 13.

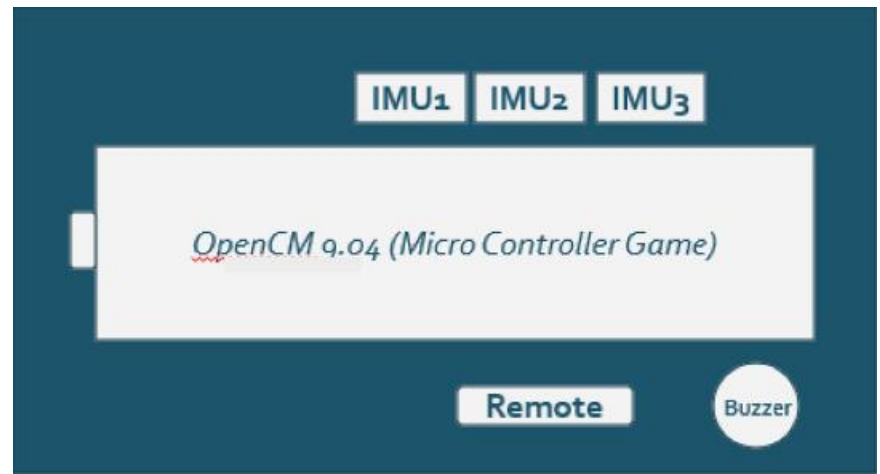

Figure 13. Grouping of features on the master console

In the 2D representation of the circuit board from the master console on the side, we can see that there are 4 groupings of the main visible elements, namely the microcontroller, IMU sensor, Remote, and Buzzer. Both the microcontroller, Remote, and Buzzer each stand on their own because they all have different functions. three IMU sockets are grouped into one because they have the same function, namely to read the sensor.

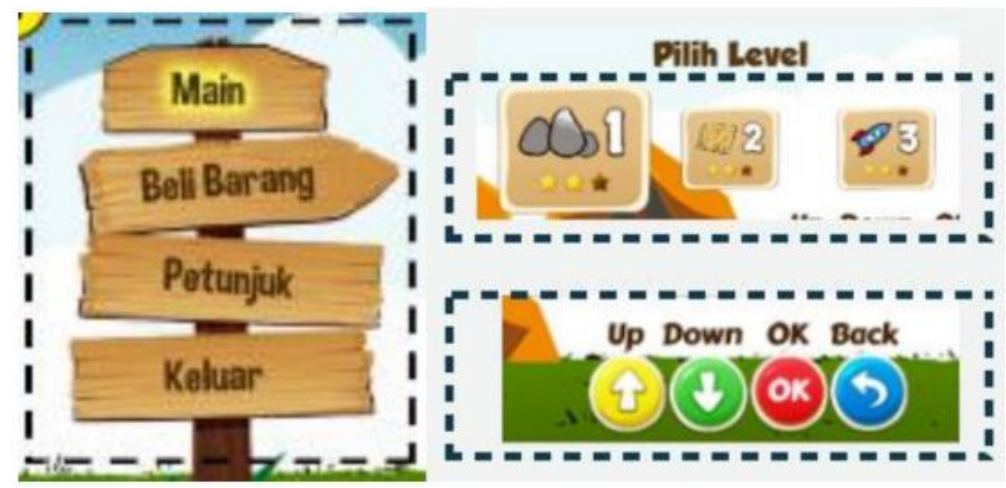

Figure 14. Grouping of features on the main menu

Grouping on the main menu interface design is shown in Figure 14. The menu display contains three menu groups, namely the main menu, submenus, and buttons navigation. Based on perceptual organization according to law Gestalt, some of the menu groupings are fulfilling with a similarity approach. Indicates that the same object will be visible simultaneously as a group, this can be determined through shape, color, direction, and size. The 
main menu is represented in labels in the form of wooden blocks and close to each other because of their own function as the main menus. Then the submenus are grouped close to each other by color and size the same because of the similarity of functions to enter a level. Navigation buttons are grouped adjacent to shapes and the same size, the same function that is as pointer navigation that makes these buttons displayed close together.

The second control setting is based on the frequency of use; that is, things that are often used are placed in that place easily accessible. For example, the remote control that is used when playing games. This remote is quite small and can be held by one hand, so users don't have to bother with closer to the computer if you want to select a menu. Remote is a game console that is often used, so it is more practical if brought by the user.

\section{CONCLUSION}

Based on several test results that have been done on the game, it can be concluded that:

- In terms of the impact of games for children, based on interviews to research objects that have played the game, the majority of them with an average percentage of $>85 \%$ stated that this game makes them aware of the benefits of scouting, they become enthusiastic following scout activities, playing scout games with embodied interaction technology is new for them and learning scout material through the game is fun.

- In terms of game performance for children, the majority of them stated that the game is quite challenging and easy to play even though almost $40 \%$ of them are still difficulty in playing it and feel the game is less challenging. This is because the object of research is just trying to play the game once and still needs to adjust to the environment and game system. But almost all children consider the game model is an interesting game and looks good too. Nearly $85 \%$ of children assume that game instruction is understandable, and the console used is a comfort to wear.

- Based on the pre-test and post-test data, it can be concluded that their insight into the scouting material increases after playing the game.

\section{Acknowledgements}

Many thanks from the authors to HI-304 PENS and all elements of AlHuda Elementary School and all my siblings that are willing to allow and support us in implementing this research.

\section{REFERENCES}

[1] A. Basuki and J. Nendra Putra, Designing and Building of 3D Adventure Game 'Tetuko: Childhood of Ghatotkacha' Using Kinect, Emit. Int. J. Eng. Technol., 2014, doi: 10.24003/emitter.v2i1.14.

[2] Y. Xu et al., Pre-patterns for designing embodied interactions in handheld augmented reality games, 2011, doi: 10.1109/ISMARAMH.2011.6093652. 
[3] S. Fuada, Perancangan Game Petualangan Pramuka Berbasis Android, J. Penerapan Ilmu-ilmu Komput., vol. 3, no. 1, pp. 18-35, 2015.

[4] I. K. Wibowo, Semantic Connection: Rancangan Platform Komunikasi pada Smart Object, J. Nas. Tek. ELEKTRO, 2016, doi: 10.25077/jnte.v5n3.312.2016.

[5] S. Bakker, A. N. Antle, and E. Van Den Hoven, Embodied metaphors in tangible interaction design, Pers. Ubiquitous Comput., 2012, doi: 10.1007/s00779-011-0410-4.

[6] S. I. Pratiwi, Pengaruh Ekstrakurikuler Pramuka terhadap Karakter Disiplin Siswa Sekolah Dasar, EDUKATIF J. ILMU Pendidik., vol. 2, no. 1, pp. 62-70, Apr. 2020, doi: 10.31004/edukatif.v2i1.90.

[7] S. Batra, The Psychosocial Development of Children: Implications for Education and Society - Erik Erikson in Context, Contemp. Educ. Dialogue, vol. 10, no. 2, pp. 249-278, Jul. 2013, doi: 10.1177/0973184913485014.

[8] J. Schell, The art of game design: A book of lenses, 3rd edition. 2019.

[9] S. Björk and J. Holopainen, Patterns in Game Design. 2005.

[10] P. Dourish, Where the Action Is: The Foundations of Embodied Interaction, Where action is Found. embodied Interact., 2001, doi: 10.1162/leon.2003.36.5.412.

[11] M. B. A. Huda, Analisis Konten Fisika dalam Kegiatan Pramuka Melalui Scouting Games, Omega J. Fis. dan Pendidik. Fis., vol. 5, no. 2, p. 40, Nov. 2019, doi: 10.31758/OmegaJPhysPhysEduc.v5i2.40.

[12] P. Marshall, Do tangible interfaces enhance learning?, 2007, doi: 10.1145/1226969.1227004.

[13] P. Marshall, S. Price, and Y. Rogers, Conceptualising tangibles to support learning, 2003, doi: 10.1145/953536.953551.

[14] M. Resnick et al., Digital manipulatives: New toys to think with, 1998.

[15] M. S. Horn and R. J. K. Jacob, Tangible programming in the classroom with tern, 2007, doi: 10.1145/1240866.1240933.

[16] A. Girouard, E. T. Solovey, L. M. Hirshfield, S. Ecott, O. Shaer, and R. J. K. Jacob, Smart Blocks: A tangible mathematical manipulative, 2007, doi: 10.1145/1226969.1227007.

[17] C. González García, D. Meana Llorián, C. Pelayo G-Bustelo, and J. M. Cueva-Lovelle, A review about Smart objects, Sensors, and Actuators, Int. J. Interact. Multimed. Artif. Intell., 2017, doi: 10.9781/ijimai.2017.431.

[18] Z. X. Yin and H. M. Xu, A wearable rehabilitation game controller using IMU sensor, 2018, doi: 10.1109/ICASI.2018.8394459.

[19] G. Kontadakis, D. Chasiouras, D. Proimaki, M. Halkiadakis, M. Fyntikaki, and K. Mania, Gamified platform for rehabilitation after total knee replacement surgery employing low cost and portable inertial measurement sensor node, Multimed. Tools Appl., vol. 79, no. 5-6, pp. 
3161-3188, Feb. 2020, doi: 10.1007/s11042-018-6572-6.

[20] Z. T. Romadon, H. Oktavianto, I. K. Wibowo, B. Sena Bayu Dewantara, E. A. Nurrohmah, and R. Adryantoro Priambudi, Pose Estimation on Soccer Robot using Data Fusion from Encoders, Inertial Sensor, and Image Data, in IES 2019 - International Electronics Symposium: The Role of Techno-Intelligence in Creating an Open Energy System Towards Energy Democracy, Proceedings, 2019, pp. 454-459, doi: 10.1109/ELECSYM.2019.8901578. 